\title{
A idade adulta: a Revista Portuguesa de Clínica Geral no último triénio
}

JAIME CORREIA DE SOUSA*

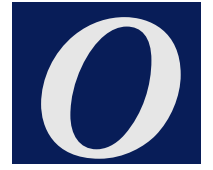
ano de 2004 ia a meio quando o Luís Pisco me convidou, em nome da Direcção Nacional da APMCG, para assumir a responsabilidade da edição da Revista Portuguesa de Clínica Geral (RPCG) a partir de 2005, sugerindo que formasse a minha própria equipa, trabalhando a partir do Porto, embora coordenando com a Publisaúde, responsável pela edição e cuja sede é em Lisboa. Respondi-lhe, na altura, que necessitava de pensar no assunto, que a responsabilidade era muito grande e precisava de tempo para perceber se conseguiria estar à altura da tarefa. Falei com o Director de então, o Armando Brito de Sá, para conhecer a estrutura e os detalhes do funcionamento da Revista, conversei com algumas pessoas a quem propus que, se eu viesse a aceitar o desafio, colaborassem como editores e percebi que iria conseguir reunir as condições mínimas para formar uma equipa editorial que permitisse dar à APMCG uma resposta positiva.

Restava saber se eu próprio me sentia capaz e se iria ter disponibilidade para me dedicar a uma nova tarefa com um peso e responsabilidade que mal adivinhava; tinha começado a trabalhar no fim de 1999 numa Unidade de Saúde Familiar em Regime Remuneratório Experimental (RRE) com todas as dificuldades iniciais pelo pioneirismo que representava; desde o início de 2004 estava empenhado a fundo na organização do ensino da Medicina Geral
Centros de Saúde no âmbito do Curso de Medicina da Escola de Ciências da Saúde (ECS) da Universidade do Minho; mantinha actividades de formação de internos e participava em vários cursos do Internato de MGF; mantinha actividades de investigação e formação ligadas ao projecto GINA (Global Initiative for Asthma) e ao Programa Nacional de Controlo da Asma, colaborava em diversos projectos com a Rede Médicos Sentinela, a APMCG, a Ordem dos Médicos, entre várias outras actividades. Como iria conseguir conciliar tudo? E os restantes elementos? Não são eles pessoas igualmente comprometidas com numerosas actividades profissionais? Teriam disponibilidade para participar no projecto? A questão era que assumir a responsabilidade pela RPCG constituía um desafio profissional muito aliciante para todos nós. O convite não vinha no melhor momento, mas tinha sido feito quando a APMCG necessitava da nossa colaboração e não podíamos recusar. Consultados os futuros colaboradores, os parceiros do RRE, os colegas da ECS e a minha família, só podia dizer que sim.

A fase seguinte foi de grande actividade preparatória; tivemos de contactar pessoas para virem a integrar o Conselho Editorial, convidar o Editor Técnico, pensar nos elementos para constituírem o Corpo de Revisores, decidir sobre a manutenção do Secretariado anterior em Lisboa, pensar no responsável pela concepção das capas, entre outras tarefas. Reunimos com a equipa cessante que nos colocou a par das 
principais questões e problemas da organização e da produção científica e técnica da Revista. Contactámos o Sr. António Leitão da Publisaúde para combinar as formas de articulação e circulação de documentos. Revimos a constituição do Conselho Científico e convidamos mais algumas personalidades que entendemos que deveriam pertencer a esse órgão da Revista. Recebemos os primeiros artigos para avaliação e demos início a todo o processo.

Foram três anos de intenso trabalho. As editoras, editores e revisores da RPCG que aceitaram a delicada tarefa de avaliar os artigos propostos desempenharam a sua actividade de forma exemplar, revelando uma inexcedivel dedicação e profissionalismo. Apesar disso, cedo verificamos que a carga de trabalho era muito elevada e necessitávamos de aumentar a equipa. Logo no início tínhamos tido uma baixa; um dos editores pediu escusa alegando tarefas académicas inadiáveis. A equipa alargou-se a mais dois elementos no fim de 2005; em Fevereiro de 2007 juntaram-se ainda mais duas editoras. A actual equipa é assim formada por mim próprio como Director e pelos Editores Ana Mateus, Benedita Graça Moura, Clara Fonseca, Filipa Almada Lobo, Helena Beça, Jesus Perez e Sanchez, Manuel Montenegro, Maria José Ribas e Raquel Braga; Henrique Botelho mantém a sua colaboração na concepção das capas; Vanda Imperial teve até há poucos meses a tarefa de recepção, encaminhamento dos artigos e contacto com os autores, tendo recentemente sido substituída por razões familiares por Cristina Mendes; temos continuado a contar com a colaboração imprescindivel de António Leitão, responsável pela Publisaúde.

Mas a Revista é sobretudo o produto dos autores; dos que enviam espontaneamente artigos e daqueles que aceitam o desafio dos editores de escrever "por encomenda" para os Dossiers, para o Clube de Leitura, para a secção POEMs ou para o Web Saúde. São os autores que fazem a Revista e a mantêm viva e actual; o que é publicado é o produto do trabalho de muitos profissionais que escolhem a RPCG como o espaço de divulgação da sua actividade. O fluxo de artigos tem sido constante, tendo-se verificado um certo aumento ao longo do triénio; a qualidade do material enviado tem vindo a aumentar, mas deve-se reconhecer que ainda há muito a fazer nesta área. Partindo de manuscritos com boas ideias e trabalhos interessantes, alguns autores apresentam um produto final que, apesar de importante, necessita de muito trabalho editorial para que possa ser publicado. Para se poder manter um nível de qualidade mínima, os Editores da Revista foram muitas vezes obrigados a redigir longos comentários editoriais que submeteram aos autores; por vezes, foi mesmo necessário reescrever secções inteiras dos artigos e propor aos autores a nova versão para que os artigos correspondessem aos padrões minimos. É por isso da mais elementar justiça reconhecer a qualidade do trabalho dos Editores a quem a RPCG e a MGF Portuguesa devem um agradecimento particular.

\section{CirCUITO do ARTIGO}

Tínhamos recebido das mãos da equipa anterior uma Revista de grande qualidade; era suposto que, no mínimo, procurássemos manter ou mesmo elevar esse nível; foi o que procurámos fazer, para o que foi considerado necessário aumentar o número de editores, diversificar o tipo de rubricas da Revista e solicitar a colaboração de um razoável número de revisores uma vez que, por decisão do Conselho Editorial, todos os artigos propostos para publicação deveriam ser apreciados por dois revisores antes da decisão de aprovação 
ou recusa de forma a garantir a isenção e imparcialidade na avaliação. Esta é também uma condição essencial para uma eventual indexação na Medline.

Todo o processo de revisão e aprovação de artigos representa o elemento-chave de uma revista cientifica. Uma vez que alguns autores que propõem artigos para publicação na RPCG comentam o tempo que decorre entre a submissão e a publicação, ou podem ficar intrigados com uma eventual recusa, sendo um assunto que, de alguma forma, poderá gerar incompreensão e animosidade, será oportuno divulgar o "Circuito do artigo" na RPCG desde a submissão à publicação de forma a evidenciar que o processo decorre de forma transparente e isenta.

O manuscrito (ou cópia electrónica) enviado pelos autores é recebido pelo secretariado da RPCG; aí, é feita a confirmação do cumprimento das normas de publicação, tais como, existência de pedido de publicação assinado pelos autores, autorizações de menção de nomes, identificação da secção da Revista à qual se propõe a publicação do artigo, nome, cargo e filiação dos autores, etc. Faltando alguns desses elementos (o que acontece na maior parte dos casos) é dirigido ao autor responsável pela correspondência o pedido dos elementos em falta. Entretanto o artigo é numerado, a ficha é inserida numa base de dados e o artigo é enviado ao Director.

Na reunião seguinte do Conselho Editorial o artigo é apresentado e proposto a um dos Editores para ser responsável pela gestão do processo de revisão. A fim de manter as regras de imparcialidade a RPCG quer que os artigos sejam sempre avaliados por dois Revisores; mas estes são profissionais que têm muitas outras tarefas e o pedido de avaliação de um artigo pode chegar às suas mãos num período de maior trabalho, pelo que a resposta pode, por vezes, demorar mais tempo do que o previsto.

Após a distribuição do artigo o/a Editor/a envia-o de forma anónima a dois Revisores que o irão apreciar de acordo com regras preestabelecidas, apoiando-se em tabelas de avaliação padronizadas. Este processo pode durar algumas semanas: o Revisor pode ter necessidade de solicitar o apoio de uma outra pessoa, por exemplo um perito em estatística, um especialista na área ou outro e necessita de justificar por escrito as suas recomendações.

Quando o Editor recebe os comentários dos revisores, se existirem ainda dúvidas ou se houver divergências substantivas entre as apreciações, poderá ter que enviar o artigo a um terceiro revisor ou perito. Concluída esta fase, o Editor apresenta as conclusões da avaliação na reunião seguinte do Conselho Editorial onde é tomada uma decisão colegial sobre o artigo; este pode ser aprovado, recusado ou serem feitas recomendações para ser melhorado, caso as propostas dos Revisores e Editor sejam nesse sentido. O Editor redige então uma carta ao autor responsável pela correspondência com a decisão do Conselho Editorial, carta essa que é remetida pelo secretariado da Revista.

Fica-se então a aguardar a resposta dos autores. Alguns autores respondem prontamente, mas a maioria demora muitas semanas ou meses a devolver o manuscrito com as alterações sugeridas. Quando a nova versão do artigo é recebida no secretariado, é remetida ao Editor responsável. Este verifica se a nova versão contempla as alterações propostas e envia de novo aos mesmos Revisores. Desde que exista alteração satisfatória do artigo de acordo com o proposto, ou se, não tendo ocorrido na totalidade, isso não afecte demasiado a possibilidade de publicação, o Editor apresenta então a nova versão do artigo ao Conselho Editorial para decisão.

No caso de haver aprovação a equipa editorial irá então proceder à prepa- 
ração do artigo (edição) revendo a ortografia, gramática e estilo linguístico, verificando se a estrutura dos quadros e as referências seguem as Normas da Revista, verificando a qualidade do resumo em inglês (Abstract), colocando o nome e filiação dos autores (que fora removido durante o processo de revisão de forma a garantir a confidencialidade) e acrescentando a data de recepção e aprovação.

O texto é então enviado à empresa editora para composição gráfica e paginação. $\mathrm{O}$ manuscrito em pdf é depois enviado aos editores e aos próprios autores para verificação, ficando pronto para ser publicado. É então elaborado o sumário para as páginas iniciais da Revista e seleccionados os títulos para a capa. Entretanto é recebida a fotografia que irá constar da capa da Revista e feita a respectiva composição gráfica.

Completado este processo a Revista fica pronta e os artigos, sumário e capa são enviados em pdf para o Portal da APMCG onde são colocados online. $\mathrm{Si}$ multaneamente a empresa gráfica prepara a edição e impressão em papel e é feito o envio aos leitores que irão recebê-la por via postal.

Todo o processo de avaliação dos artigos foi, assim, organizado de acordo com as regras sugeridas nas "Normas de Vancouver", ${ }^{1}$ cuja tradução actualizada se publica neste número. Para além das duas actualizações das "Normas de Publicação" realizadas durante o triénio, ${ }^{2,3}$ esta publicação é mais um elemento que demonstra o esforço que os Editores e Revisores da RPCG têm colocado na melhoria da qualidade dos artigos publicados.

É compreensivel que alguns autores que despenderam muito tempo e esforço na preparação do artigo que submetem à RPCG se sintam frustrados quando este lhes é devolvido com sugestões de alteração por vezes substantivas. Não existe acesso fácil por parte de todos os autores a consultores em meto- dologias de investigação ou estatística que os possam ajudar a preparar os manuscritos de forma a obterem fácil aprovação. Apesar disso, muito se tem feito nos últimos anos para aumentar o nivel de qualidade da investigação e o resultado está aí à vista nas páginas da RPCG. Sendo um facto que a qualidade dos pedidos de publicação que têm sido endereçados à Revista tem vindo a aumentar, também continua a ser verdade que ainda há muito a fazer por parte dos próprios autores em relação à qualidade dos manuscritos que enviam. A simples leitura cuidada do conjunto de normas em vigor e a observação dos seus critérios pode evitar aos Editores e Revisores o consumo de tempo em tarefas essencialmente editoriais que têm que conciliar com as tarefas de revisão técnica e científica.

A RPCG deve assim uma palavra especial de agradecimento a todos os revisores que entre 2005 e 2007 colaboraram nas tarefas de revisão e cujos nomes podem ser lidos no Quadro I, apesar da responsabilidade pela revisão de cada artigo em particular ser confidencial. Graças a eles, durante estes três anos foi possivel produzir uma revista de qualidade e com publicação regular.

\section{Inovação e desenvolvimento}

Desde o início que esta equipa procurou alargar o leque de oferta editorial aos leitores da RPCG tendo assim sido criada no último número de 2005 a secção "POEMs". Procuraram-se outras secções que chegaram a estar pensadas mas não foi possivel concretizá-las. Entre elas conta-se a ideia de se publicar em cada número um "Olho Clínico", não apenas quando algum autor o propusesse, mas, à semelhança do Clube de Leitura ou POEMs, por iniciativa (encomenda) da equipa editorial. Face à inexistência de artigos da iniciativa espontânea de autores para a secção "Forma- 


\begin{tabular}{|lll|}
\hline \multicolumn{2}{|c|}{ LISTA DE REVISORES QUE COLABORARAM COM A RPCG ENTRE 2005 E 2007} \\
\hline Abílio Malheiro & Conceição Outeirinho & \multicolumn{1}{c|}{ Luísa Carvalho } \\
Aida Fernandes & Constantina Sousa e Silva & Maria da Paz Trigueiros \\
Alberto Pinto Hespanhol & Cristina Galvão & Mário Freitas \\
Ana Ferrão & Edmundo Sá & Mário Santos \\
Ana Marques Almeida & Fátima Aguiar & Miguel Melo \\
Ana Pisco & Graça Veiga & Mónica Granja \\
André Biscaia & Isabel Santos & Nuno Borges \\
Ângela Teixeira & João Sequeira Carlos & Osvaldo Santos \\
António Rodrigues & John Yaphe & Rosalvo Almeida \\
António Sarmento & Jorge Brandão & Susana Cadilhe \\
Armando Brito de Sá & José Nunes & Teresa Libório \\
Carlos Canhota & José Sampaio & Vítor Ramos \\
Carlos Martins & Duarte Luciana Monteiro & \\
\hline
\end{tabular}

ção", destinada à publicação de relatos de projectos ou experiências em educação médica, pensou-se fazer o mesmo para incentivar o aparecimento de artigos, ideia igualmente não concretizada por limitações de tempo e de recursos humanos da equipa editorial.

Outra iniciativa dos Editores foi tentar concretizar uma velha aspiração dos autores portugueses na área da MGF, o ter uma revista indexada na Medline. Em Outubro de 2007 foi apresentada nova proposta formal à National Library of Medicine (NLM). A maior parte dos critérios de indexação na Medline previstos pela NLM são já cumpridos pela RPCG, pelo que se espera que possamos vir a ter uma resposta positiva, embora deva existir alguma reserva face a este optimismo.

No âmbito do processo de renovação do Portal da APMCG em curso, foi programada com a empresa responsável pela concepção e gestão, a Wiremaze, a renovação da área da RPCG com os seguintes objectivos: a área da RPCG estar acessivel a partir do Portal; o número mais recente da RPCG estar disponível sujeito às condições de acesso determinadas pela APMCG; a edição electrónica da RPCG anteceder a edição em papel; a área da RPCG no Portal permitir o acesso a todos os números da RPCG disponíveis em pdf; ser criado um motor de busca que permita a procura de artigos disponiveis em números anteriores por pesquisa por vários campos. A preparação desta área ainda não está concluída, podendo demorar alguns meses pela quantidade de trabalho que obriga em relação aos números mais antigos da Revista, não existentes em pdf. A concretização da renovação desta área do Portal constituirá seguramente um importantíssimo instrumento de trabalho cientifico para os autores de língua portuguesa.

Ao planear a sua participação no Congresso da WONCA em Paris, a Direcção da APMCG solicitou à Redacção da RPCG que organizasse um número especial em inglês, destinado a ser distribuído aos participantes; tratou-se de uma edição limitada, não distribuída aos leitores, mas que foi colocada no site da APMCG em Outubro de 2007. Deste Número Especial constavam três editoriais ${ }^{4-6} \mathrm{e}$ um artigo sobre o desenvolvimento da MGF em Portugal, ${ }^{7}$ todos eles inéditos, bem assim como alguns artigos anteriormente publicados na Revista em lingua inglesa, uma selec- 
ção de abstracts de artigos de edições anteriores e a tradução de alguns Clube de Leitura, POEMs e Web Saúde. Esta edição teve uma recepção muito satisfatória entre os participantes na WONCA-Paris.

\section{BALANÇO DE ACTIVIDADE}

Ao terminar a nossa tarefa como responsáveis pela RPCG impõe-se fazer um balanço da actividade ao longo destes três anos. Em dois editoriais anteriores reflectimos já sobre a actividade da Revista em cada ano. ${ }^{8.9}$ É interessante agora fazer uma análise global do que foi a actividade de publicação da Revista no triénio.

No Quadro II apresenta-se o conjunto de artigos publicados de 2005 a 2007 por secção da RPCG e ano de publicação. No total dos três anos foram publicados 18 números, ${ }^{\S}$ num total de 2.212
$(640+768+804)$ páginas e 252 artigos," em média 14 artigos por revista. Houve um aumento ligeiro e progressivo da média de artigos por revista: 11,7 (2005), 14,8 (2006) e 15,5 (2007).

Os artigos da iniciativa dos autores (Estudos Originais, Revisões, Resumos de Congressos, etc.) corresponderam a $32,5 \%$ do total de rubricas publicadas; os artigos da iniciativa dos Editores (Editoriais e artigos dos Dossiers) totalizaram $44,1 \%$ e as restantes secções (Documentos, Clube de Leitura, POEMs e Web Saúde) 32,5\%.

No Quadro III observa-se a distribuição dos artigos da iniciativa dos autores publicados em 2005-2007 na RPCG. As rubricas "Estudos Originais" e "Revisões" constituíram, em conjunto, $59,7 \%$ dos artigos publicados da iniciativa de autores. Os leitores da Revista estiveram pouco activos; as cartas ao Director constituíram apenas $1,2 \%$ da iniciativa de autores; esta é uma área

QUADRO II

\begin{tabular}{|c|c|c|c|c|c|c|c|c|}
\hline \multicolumn{9}{|c|}{ QUADRO II } \\
\hline \multicolumn{9}{|c|}{ ARTIGOS PUBLICADOS EM 2005-07 POR SECĈ̣̃O DA RPCG E ANO DE PUBLICAC̣̃̃O } \\
\hline & \multicolumn{2}{|c|}{2005} & \multicolumn{2}{|c|}{2006} & \multicolumn{2}{|c|}{2007} & \multicolumn{2}{|c|}{ 2005-07 } \\
\hline & $n$ & $\%$ & $n$ & $\%$ & $n$ & $\%$ & $n$ & $\%$ \\
\hline Editoriais & 6 & 8,6 & 7 & 7,9 & 9 & 9,7 & 22 & 8,7 \\
\hline Editoriais Dossier & 5 & 7,1 & 6 & 6,7 & 6 & 6,5 & 17 & 6,7 \\
\hline Artigos Dossier & 19 & 27,1 & 27 & 30,3 & 26 & 28,0 & 72 & 28,6 \\
\hline Clube de Leitura & 6 & 8,6 & 6 & 6,7 & 6 & 6,5 & 18 & 7,1 \\
\hline Web Saúde & 6 & 8,6 & 6 & 6,7 & 6 & 6,5 & 18 & 7,1 \\
\hline POEM & 1 & 1,4 & 6 & 6,7 & 6 & 6,5 & 13 & 5,2 \\
\hline Documentos & 3 & 4,3 & 3 & 3,4 & 4 & 4,3 & 10 & 4,0 \\
\hline Estudos Originais & 12 & 17,1 & 12 & 13,5 & 13 & 14,0 & 37 & 14,7 \\
\hline Revisões & 2 & 2,9 & 5 & 5,6 & 5 & 5,4 & 12 & 4,8 \\
\hline Opinião e Debate & 2 & 2,9 & 4 & 4,5 & 4 & 4,3 & 10 & 4,0 \\
\hline Relatos de Casos & 2 & 2,9 & 2 & 2,2 & 3 & 3,2 & 7 & 2,8 \\
\hline Resumos de Congressos & 0 & 0,0 & 2 & 2,2 & 3 & 3,2 & 5 & 2,0 \\
\hline Artigos Breves & 1 & 0,0 & 1 & 1,1 & 2 & 2,2 & 4 & 1,6 \\
\hline Prática & 2 & 2,9 & 1 & 1,1 & 0 & 0,0 & 3 & 1,2 \\
\hline Formação & 1 & 1,4 & 0 & 0,0 & 0 & 0,0 & 1 & 0,4 \\
\hline Olho Clínico & 1 & 1,4 & 0 & 0,0 & 0 & 0,0 & 1 & 0,4 \\
\hline Testemunho & 1 & 1,4 & 0 & 0,0 & 0 & 0,0 & 1 & 0,4 \\
\hline Cartas ao Director & 0 & 0,0 & 1 & 1,1 & 0 & 0,0 & 1 & 0,4 \\
\hline Total & 70 & 100 & 89 & 100 & 93 & 100 & 252 & 100 \\
\hline
\end{tabular}


QUADRO III

\section{ARTIGOS DA INICIATIVA DOS AUTORES PUBLICADOS EM 2005-07 NA RPCG POR SECC̣̃̃O}

\begin{tabular}{lc|c}
\hline & $\mathbf{n}$ & $\%$ \\
\hline Estudos Originais & 37 & 45,1 \\
\hline Revisões & 12 & 14,6 \\
\hline Opinião e Debate & 10 & 12,2 \\
\hline Relatos de Casos & 7 & 8,5 \\
\hline Resumos de Congressos & 5 & 6,1 \\
\hline Artigos Breves & 4 & 4,9 \\
\hline Prática & 3 & 3,7 \\
\hline Formação & 1 & 1,2 \\
\hline Testemunho & 1 & 1,2 \\
\hline Olho Clínico & 1 & 1,2 \\
\hline Cartas ao Director & 1 & 1,2 \\
\hline Total & 82 & 100
\end{tabular}

em que o contributo espontâneo dos leitores teria sido importante.

Com esta edição, termina a responsabilidade da presente equipa e como sempre nestas circunstâncias existem alguns sentimentos contraditórios: por um lado sentimos um grande alívio por deixar de ter esta tarefa tão pesada a nosso cargo; por outro sentimos um certo pesar e sensação de saudade, já que se tratou de um trabalho cientificamente muito estimulante e que nos fez aprender muito e contribuiu para o nosso desenvolvimento profissional. Esperamos ter conseguido corresponder ao desafio que nos foi feito há três anos e ter dado o nosso contributo para elevar o nível científico da MGF Portuguesa.

Inicia-se agora um novo período sob a responsabilidade de novos Editores coordenados pelo futuro Director, António Faria Vaz, a quem desejamos as maiores felicidades. A Revista cresceu, amadureceu e parece ter já atingido a sua idade adulta. O futuro corpo edito- rial saberá seguramente estar à altura dos novos desafios que se adivinham. Estamos seguros de que saberão pegar no testemunho e continuar a fazer chegar a todos nós uma Revista de grande qualidade e com a qual a MGF Portuguesa se sinta orgulhosa.

\section{REFERÊNCIAS BIBLIOGRÁFICAS}

1. Comissão Internacional de Editores de Revistas Médicas. Requisitos uniformes para manuscritos submetidos a revistas médicas. Rev Port Clin Geral 2007 Nov-Dez; 27:778-98.

2. Conselho Editorial da Revista Portuguesa de Clínica Geral. Normas para apresentação de artigos à Revista Portuguesa de Clínica Geral. Rev Port Clin Geral 2005 Jan-Fev; 21 (1): 99-104.

3. Conselho Editorial da Revista Portuguesa de Clínica Geral. Normas para apresentação de artigos à Revista Portuguesa de Clínica Geral. Rev Port Clin Geral 2007 Jan-Fev; 23 (1): 75-82.

4. Sousa JC. A very unique journal. Rev Port Clin Geral 2007 Oct; 23 (SI) : 5.

5. Švab I. Academic Family Medicine - the jewel in the crown or the useless aristocrat? Rev Port Clin Geral 2007 Oct; 23 (SI): 6-8.

6. Yaphe J. Teaching and learning about empowerment in family medicine. Rev Port Clin Geral 2007 Oct; 23 (SI): 11-3.

7. Sousa JC, Pisco L. Changing the face of Portuguese Family Medicine: an overview of the recent history of family medicine in Portugal. Rev Port Clin Geral 2007 Oct; 23 (SI): 14-20.

8. Sousa JC. Uma grande equipa. Rev Port Clin Geral 2006 Jan-Fev; 22 (1): 9-11.

9. Sousa JC. Dois anos com a Revista Portuguesa de Clínica Geral. Rev Port Clin Geral 2007 Jan-Fev; 23 (1): 9-12.

§ Para estes cálculos não se considerou a edição especial em inglês.

**Para efeitos deste cálculo considerou-se como texto cada conjunto de textos (POEM's, Clube de Leitura, Web Saúde ou Resumos de Congressos). 